University of South Carolina

Scholar Commons

Faculty Publications

Languages, Literatures and Cultures,

Department of

Summer 6-21-2020

Restructuring a Beginner Language Program: A Quantitative Analysis of Face-to-Face Versus Flipped-Blended Spanish Instruction

Nina Moreno

University of South Carolina - Columbia, morenon@mailbox.sc.edu

Paul Malovrh

Follow this and additional works at: https://scholarcommons.sc.edu/dllc_facpub

Part of the Applied Linguistics Commons, and the First and Second Language Acquisition Commons

Publication Info

Reprinted from Hispania, ed. AATSP, Volume 103, Issue 2, Summer 2020, pages 259-274.

(C) 2020, AATSP

This Article is brought to you by the Languages, Literatures and Cultures, Department of at Scholar Commons. It has been accepted for inclusion in Faculty Publications by an authorized administrator of Scholar Commons. For more information, please contact digres@mailbox.sc.edu. 


\title{
Restructuring a Beginner Language Program: A Quantitative Analysis of Face-To-Face versus Flipped-Blended Spanish Instruction
}
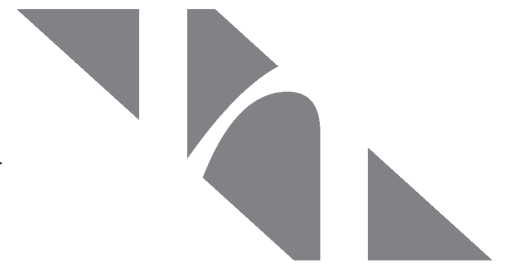

Nina Moreno

University of South Carolina

Paul A. Malovrh

University of South Carolina

\begin{abstract}
The present study provides empirical data measuring the effects of a flipped and blended course design for beginning-level Spanish on the four skills of reading, writing, speaking, and listening, compared to a control group following a traditional present-practice-produce instructional format. The study provides a template for the successful restructuring of language programs through the incorporation of a cognitive model of learning processes, controls for depth of language processing, and a reconceptualization of instructional context. Results of a pre/post-test design show that two experimental groups, which met three days per week in the classroom along with flipped-blended course work, developed at the same pace in receptive skills, and more so in productive skills, than a control group that met four days per week only in the classroom.
\end{abstract}

Keywords: blended instruction/instrucción semipresencial, depth of processing/profundidad de procesamiento, flipped course design/aprendizaje invertido, learning context/contexto de aprendizaje, language program restructuring/restructuración de programas de lengua, second language processing/procesamiento de segundas lenguas, stages of learning/etapas de aprendizaje

\section{Introduction}

$\mathrm{T}$ he restructuring of foreign language programs among American institutions of higher learning has been a popular topic over the past ten years. The oft-cited Modern Language Association's (MLA) 2007 report, "Foreign Languages and Higher Education: New Structures for a Changed World," put out a call for program-wide change, with the aim of meeting the growing need for foreign language users in the globalized post-9/11 era (see "Foreign Languages"). The report was based on findings of a special committee formed in 2004 with the task of investigating the future of foreign language education. Among its findings was that the traditional two-tier program design, in which beginner language instruction and upper-division core (major) courses are treated as separate bodies, is disconnected from proficiency-based outcomes that are most in demand by professions involved with foreign language use. Five years later, in the MLA's 2012 Presidential Address, a more visible relationship between Second Language Acquisition (SLA) theory and foreign language program design was cited as a necessary ingredient for any effective and longstanding changes to be made (Berman 2012). The MLA's position impacted the profession considerably. First, it established a context in which the various agents of foreign language education could acknowledge and discuss a serious problem in higher education: that the design of foreign language programs is archaic and out of touch with societal and global demands. Second, it acknowledged that experts in language learning and teaching 
would be required to reconceptualize learning outcomes and to identify the ways in which the benefits of formal instruction could be maximized in order to achieve them. Change would require the coming together of various actors, ranging from program directors to department chairs, experts in SLA and foreign language pedagogy, and faculty representing different core disciplines, in order to rethink program-wide outcomes of language learning, as well as how language should be taught to better prepare students upon graduation.

In the twelve years that have passed since the MLA's initial call for restructuring, several studies have examined what sort of progress has been made. VanPatten's (2015) white paper, for example, counted the number of SLA and/or applied linguistics experts across samples of institutions around the country and found a lack of expertise among foreign language departments; such experts represented $20 \%$ of tenure-track faculty in Spanish programs, and $8 \%$ in French programs. In addition, a January 2017 issue of Inside Higher Ed reported a recent survey that found out of the 134 professors and administrators who responded, more than half had read the MLA 2007 report, while only 39\% had actually made efforts to make program changes (Redden 2017). The authors concluded that change is slow, but that foreign language programs still need to undergo restructuring if they are to remain players in higher education. More recent research has noted several reasons for the delays, ranging from a lack of uniformity in teaching methods within language programs to a lack of dissemination of preexisting research regarding best teaching practices, a misuse of technology for appropriate implementation and delivery of sound pedagogy, and a lack of communication between faculty and administration (Malovrh and Benati 2018; Malovrh and Moreno 2018). Malovrh and Moreno concluded the main catalyst for the lack of restructuring is not a shortage of professional knowledge, but rather a constraining academic culture resistant to change.

The present report documents changes implemented in the Spanish Program at the University of South Carolina, in the form of a pre-/post-test pilot study, comparing two (experimental) flipped-blended Spanish courses to a (control) traditional face-to-face course, which used a present-practice-produce (PPP) method. The purpose of the report is to provide an example of how beginner language program restructuring has been undertaken successfully at a large Research I university in which a beginning Spanish course may involve up to forty sections, each with an enrollment of twenty-five students. In doing so, we provide empirical data to demonstrate measurable changes in learning outcomes across the four skill areas of reading, speaking, listening, and writing. Our report focuses on one particular aspect of the MLA's call for restructuring: the incorporation of SLA research into the design and administration of language pedagogy. The aim is to continue the discussion across the profession regarding how to best intervene with and affect the learning process, and how to enforce uniform practices among a large pool of practitioners, as a means to achieving proficiency-based learning outcomes.

\section{Review of Literature}

Restructuring a language program begins with answering fundamental questions: Who is designing the language curriculum? How can a curriculum be delivered with uniformity across forty sections? Is the curriculum well-grounded in contemporary theories of language learning? And how many hours of instruction are needed for the desired learning outcomes to be met? The last question then engenders many other questions related to institutional resources. How many classrooms can be scheduled throughout the week? If the university is a flagship institution, how will restructuring affect satellite and regional campuses? Recent literature on the topic makes it clear that there are no easy answers. Teacher training within large programs tends to be superficial and lacks dissemination of theories regarding how languages are learned (Moreno 2014), and research has shown that teacher characteristics is a variable that may affect classroom learning (Gurzynski-Weiss 2013). With regard to who is designing curricula, VanPatten (2015) showed that institutions of higher education largely fail to utilize experts in SLA; even though 
(re)structuring guides have existed for decades, as well as prescribed approaches for effective communicate practices, it is debatable whether or not such practices are effectively implemented (VanPatten, 2015).The question regarding whether or not SLA theory is closely associated with pedagogy, therefore, is still relevant, though unclear (Ellis 2016).

Meanwhile, we know that instruction helps second language learners (L2) develop in the four skill areas (DeKeyser and Prieto Botana 2013), that processing input and practiced output are crucial to the learning process (VanPatten and Williams 2007), and that noticing input and making form-meaning connections is the learner's most basic and fundamental task (Leow 2015). Perhaps the question that best synthesizes the challenges facing language program directors was posited by DeKeyser and Prieto Botana (2013), one that asked how we are able to find the class time to provide input, opportunities for practiced output, and instructional feedback, in order to meet desired learning outcomes. By deconstructing the layers of curricular and pedagogical nuances embedded in such a question, we arrived at a series of programmatic issues to be addressed in order to make significant curricular change: 1) How can face-to-face class time be used more efficiently for practiced output and instructional feedback? 2) How can uniformity of teaching design and method be implemented across forty sections? 3) How can up to date research in SLA be used to affect the learning process and maximize the effect of formal instruction? And 4), how can proficiency-based learning outcomes be achieved within the constraints of university resources (i.e., class time and space)? In order to address such issues, we focus on the process of learning, the depth of processing, and the context (i.e., place) of instruction. To that end, we briefly review one cognitive model of $\mathrm{L} 2$ learning as a framework for a flipped course design, the notion of depth of processing, and a blended (i.e., computer and face-to-face) model for the delivery of instruction, in order to establish a template for beginner language program restructuring.

\section{L2 Learning Process and Product}

Leow's (2015) framework of the L2 learning process in Instructed Second Language Acquisition (ISLA) addresses the processes and products involved with learning, in the form of five stages, starting with the exposure to input stage and concluding with the output (production) stage. ${ }^{1}$ The framework is schematized in Figure 1.

\begin{tabular}{lllllll}
\hline INPUT & $\{>$ & INTAKE & $>$ & $\begin{array}{l}\text { INTERNAL } \\
\text { SYSTEM }\end{array}$ & $>\}$ & OUTPUT \\
& Stage 1 & Stage 2 & Stage 3 & Stage 4 & Stage 5 & \\
\hline (product) & (process) & (product) & (process) & (product) & (process) & (product) \\
(input) & (input) & (intake) & (intake) & $\begin{array}{l}\text { (L2 } \\
\text { knowledge) }\end{array}$ & $\begin{array}{l}\text { L2 } \\
\text { knowledge / } \\
\text { output }\end{array}$ & $\begin{array}{l}\text { Lepresentative } \\
\text { Knowledge }\end{array}$ \\
\hline
\end{tabular}

Figure 1. Leow's (2015) framework of the L2 learning processes in ISLA

In the framework, learning is conceptualized either as a process, or as a product, all of which occurs between input and output. Stage 1 represents the learner's process of converting a subset of the incoming L2 input into preliminary intake. Stage 2 is the intake-the product of the previous stage - and, if further processed, is available for stage 3, in which the intake is processed (e.g., assigning meaning to form) into L2 knowledge. Stage 4 is the L2 knowledge, the 
product of the previous stage, and stage 5 involves the process of converting L2 knowledge into output (i.e., production). This production allows for feedback, which in turn may loop back to Stage 1 with the potential for restructuring L2 learners' inaccurate knowledge (see Leow 2015 for elaboration).

If we consider Leow's framework from a pedagogical perspective, we begin by exploring how linguistic input can be introduced to the L2 learner at stage 1, how instruction may intervene to enhance the learner's ability to convert input to intake, how and when to provide opportunities to convert intake to output, and finally, how and when to provide corrective feedback to the learner. Different approaches have aimed to expedite the learning process through different levels of pedagogical intervention. VanPatten's Processing Instruction (1996; 2004), for example, provides explicit information regarding grammar and processing strategies; it also structures the target input and presents it to the learner one form at a time, with the aim of increasing the likelihood that L2 learners notice and assign native-like meaning to structure(s) that they would otherwise naturally misinterpret, or not even notice. Krashen and Terrell's Natural Approach (1983), as another example, asserts that instruction should flood the L2 learners with input, and allow their internal syllabus to govern their L2 development. That is, it asserts that L2 learners will notice the input they are developmentally ready to notice, and will learn the L2 according to a route that is cognitively and psycholinguistically governed. There are many other approaches to teaching, and the field of ISLA is in no shortage of debate over which method is superior to the other. Such debate is outside of the scope of the present study, however. What is relevant is that they acknowledge a similar learning process to that which is represented in Leow's framework. There is no debate that the sequence of learning begins with input, is then converted to intake, and then leads to the development of a linguistic system, from which production is derived. From a curricular perspective, the question is how a teaching method can adhere to underlying models of learning in its design, and how it can be packaged and articulated in order to meet specific learning outcomes, while maximizing the effects of formal instruction.

\section{Depth of L2 Processing}

Maximizing the effect of instruction is not limited to the L2 learners' ability to notice input, to assign it meaning, and to produce it in communicative contexts. It also entails the learner's ability to retain information in long-term memory and to develop the four skills of communication. A longstanding debate continues to unfold in the field of ISLA regarding which types of instruction best facilitate retention of the target language. Many researchers believe that deductive approaches expedite learning because they allow the learning to quickly identify first language (L1) sources of confusion and correct them (Carroll 2001), and that knowing explicit rules about language primes a learner to look for particular structures in the L2 input (Ellis 2002). Other researchers favor guided inductive learning, citing that L2 learners are more actively engaged with the L2 input, are required to analyze it more thoroughly through hypothesis testing, and therefore process it more deeply and retain it in long-term memory (Leow 2015). Whether deductive or inductive learning leads to more efficient learning and greater retention, or whether explicit versus implicit instruction is superior, are issues that far exceed the scope of the present study. What is in focus, however, is that there are different depths of processing input, and that practitioners need to be aware of their effect on the retention of that which is learned. The notion of depth of processing has received considerable attention in the field of cognitive psychology and is receiving increasingly more attention in SLA as well. It is defined as follows:

Depth of processing is the relative amount of cognitive effort, level of analysis, and elaboration of intake, together with the usage of prior knowledge, hypothesis testing, and rule formation employed in de-coding and encoding some grammatical or lexical item in the input. (Leow 2015: 204) 
Different tasks, task designs, and language use require varying levels of processing. Listening to a lecture and taking notes, for example, require a passive form of engagement with input, compared to listening to a lecture and being asked to create a conceptual map based on it, which would require an active engagement with the input. With regard to L2 instruction, providing learners with explicit rules to follow, as opposed to having them read a text and try to create a grammatical rule on their own, would require less depth of processing, but may also allow for more practice time during a class session (Leow 2015). Different methods have been devised to employ both learning approaches. Traditionally, teachers followed a PPP design; they presented input and explicit instruction of grammar; learners then practiced the material; and then, learners produced something, all of which follows a highly deductive approach to learning. More recent methods, however, such as the PACE model (Adair-Hauck et al. 2010), employ a more inductive approach, known as guided induction. In this dialogic model, the instruction of grammar is based on the use of written stories from which learners extract the correct usage of the target structure and, with their instructor's help, make form-meaning connections (Donato and Adair-Hauck 2016). It begins with presenting (P) learners with input, then bringing their attention (A) to a certain linguistic structure, then asking them to co-construct $(\mathrm{C})$ a rule about how to use the structure, and then extending (E) the rule to another task. The PACE method requires a higher level of cognitive effort, level of analysis, and use of prior knowledge, as learners attempt to form a hypothesis about certain form-meaning connections. More recent research suggests that guided induction, particularly in online learning contexts and from a psycholinguistic perspective, has had superior effects on learning processes and outcomes (Cerezo et al. 2016; Zhuang 2019). ${ }^{2}$

Referring back to Figure 1, depth of processing is relevant at stage 1 for converting input to intake, at stage 3 for converting intake into linguistic knowledge, and at stage 5 for converting linguistic knowledge to output. From a pedagogical perspective, the goal is to create tasks at those stages that require greater depth of processing, and to increase the likelihood that learners will retain new information. The challenge, then, is to find the instructional time required to implement methods, such as PACE, that require greater depths of processing, but not at the detriment of the time required for practiced output and corrective feedback. In other words, the pedagogical design becomes more logistically challenging, and must be formatted according to constraints of class time and space. In addition, a pedagogy grounded in a specific cognitive framework of learning, and utilizing tasks requiring different depths of processing, must be implemented with relative uniformity, across forty sections, taught by instructors with varying levels of training, yet who are all working to achieve common learning outcomes. Such challenges necessitate a rethinking of instructional context, as it relates to location and delivery.

\section{Context: Blending Online and Face-to-Face Instruction in a Flipped Format}

Learning context has been a popular strand of research in SLA (Norris and Ortega 2000). The most common dichotomy explored has been learning in contexts of formal instruction versus naturalistic settings. Beginning with Krashen's Monitor Model (1982), researchers have debated whether classroom instruction correlates with learned (explicit) knowledge, and naturalistic settings with acquired (implicit) knowledge, while others have argued for a strong interface position, positing that explicit knowledge becomes implicit knowledge (DeKeyser 2007). ${ }^{3}$ Regardless of the theoretical position, it has been well documented that learning context affects outcomes; each context employs distinct processes. Whereas formal instruction entails explicit teaching of rules and language, naturalistic contexts of immersion afford learners with more time to internalize, analyze, and hypothesize about language (Leow and Cerezo 2016). Meanwhile, the notion of context is undergoing constant change and is being redefined, due to the increase of online instruction in the era of computer-assisted language learning (CALL) (Allen and Seaman 2014). Such change has blurred the distinction between learning contexts 
and has caused some researchers to reject the traditional dichotomy. Loewen (2015), for example, asserts that the importance of location on learning should now be considered along with the degree to which learning processes are altered through intervention, a context he refers to as "attempted acquisition." That is, CALL may establish contexts in which different learning processes may be manipulated, thus having profound influence on curricula employing online, hybrid, or blended course designs.

Blended course designs provide an ideal context in which to provide instruction based on Leow's (2015) framework. ${ }^{4}$ By using technology as a medium, a flipped course design makes it possible to provide L2 learners with input, as well as the appropriate tasks requiring higher levels of cognitive effort and active engagement with the target language, thus increasing the depth of processing as input is converted to intake. By locating the initial learning process in a computerized format for the students to complete before coming to class, they are allowed more time to internalize language; they may be afforded opportunities for guided induction and hypothesis testing, and more time for linguistic analysis (Cerezo et al. 2015). By doing so, more classroom time may be reserved exclusively for practiced output and corrective feedback (Cerezo et al. 2016; Leow et al. 2019). Figure 2 provides Leow's framework, conceptualized in terms of a blended and flipped course design, with that information in italics.

\begin{tabular}{|c|c|c|c|c|c|c|}
\hline \multirow[t]{2}{*}{ INPUT } & $\{>$ & INTAKE & $>$ & $\begin{array}{l}\text { INTERNAL } \\
\text { SYSTEM }\end{array}$ & $>\}$ & \multirow[t]{2}{*}{ OUTPUT } \\
\hline & Stage 1 & Stage 2 & Stage 3 & Stage 4 & Stage 5 & \\
\hline (product) & (process) & (product) & (process) & (product) & (process) & (product) \\
\hline \multirow[t]{3}{*}{ (input) } & (input) & (intake) & (intake) & $\begin{array}{l}\text { (L2 } \\
\text { knowledge) }\end{array}$ & $\begin{array}{l}\text { L2 } \\
\text { knowledge / } \\
\text { output }\end{array}$ & $\begin{array}{l}\text { representative } \\
\text { L2 } \\
\text { Knowledge }\end{array}$ \\
\hline & $\begin{array}{l}+ \text { flipped } \\
\text { (at home) }\end{array}$ & $\begin{array}{l}+ \text { flipped } \\
\text { (at home) }\end{array}$ & $\begin{array}{l}+ \text { flipped } \\
\text { (at home) }\end{array}$ & $\begin{array}{l}\text { + flipped } \\
\text { (at home) }\end{array}$ & $\begin{array}{l}\text { - flipped } \\
\text { (classroom) }\end{array}$ & \\
\hline & Computer & Computer & Computer & Computer & Face-to-Face & \\
\hline
\end{tabular}

Figure 2. Leow's (2015) framework applied to a blended and flipped format

Using the model for course design provided in Figure 2, several changes to traditional course structure may be implemented. First, greater depth of processing may be achieved by using homework as a learning tool before classroom work begins, which will yield a greater amount of class time dedicated exclusively to language production and practice. Second, greater uniformity among large multi-section courses may be achieved by having instructional design, grounded in a specific cognitive framework of learning, centralized in one computerized delivery system. Third, the additional class time may be utilized for learning other content, such as cultural and literary analysis. Finally, we hypothesize that such restructuring may allow for a reconceptualization of learning outcomes toward more proficiency-based language development. To that end, we posit the following research questions:

1. What is the effect of a flipped and blended course design on the development of speaking, writing, listening, and reading, compared to a traditional course design, over the course of one semester of university instruction?

2. What are L2 learner perceptions of a flipped and blended course design? 


\section{Method}

In the following section we present the pre- and post-test design we followed to gather relevant data on proficiency as well as a survey that guided this study to: 1) compare the proposed flipped-blended model applied to both pilot courses (here referred to as our experimental sections) and the existing traditional model; 2) establish which set of materials would adapt better to our curriculum and departmental demands (such as space and time restrictions); and 3) investigate student perceptions about a novel learning model and their own learning process.

\section{Participants}

The original pool of participants in this study consisted of sixty-two undergraduate students in the Spanish Program at the University of South Carolina. The final number of participants was fifty-eight (women, $n=33$; men, $n=25$ ) after eliminating the few who missed the posttest. The native language of the participants was English, and all had, on average, one to two years of previous Spanish language instruction at the high school level. Upon arrival to the university, all were enrolled in a beginner-level Spanish class as per a departmental placement test score. The control and experimental groups were whole classes and each had a different instructor. The instructor of the control group was an experienced graduate teaching assistant who had previously taken a graduate course regarding foreign-language teaching methodology and SLA theory. In addition, he was familiar with the restructuring process of the program. The participants in both experimental sections were recruited during the placement test period through flyers that advertised the opportunity to participate in a pilot course with innovative technology, fewer days of face-to-face instruction, and the incentive of free materials. The two researchers, both experts in SLA and pedagogy, each taught one of the experimental sections. The control group (C) followed a traditional, teacher-centered PPP approach to teaching and learning and met face-to-face for fifty minutes four times per week. The experimental groups (A) and (B) each followed a flipped-blended format. They only met three times per week for fifty-minute face-to-face interaction but had a more controlled online homework agenda that took between one to three hours of work before each face-to-face session.

\section{Table 1. Group descriptions ${ }^{\star}$}

\begin{tabular}{|c|c|c|}
\hline Group A $(n=19)$ & Group B $(n=20)$ & Group C $(n=23)$ \\
\hline Flipped and blended approach & Flipped and blended approach & Traditional, PPP approach \\
\hline $\begin{array}{l}\text { Meets } 3 \text { times a week F-to-F, total } \\
\text { of } 150 \text { mins }\end{array}$ & $\begin{array}{l}\text { Meets } 3 \text { times a week F-to-F, total } \\
\text { of } 150 \text { mins }\end{array}$ & $\begin{array}{l}\text { Meets } 4 \text { times a week F-to-F, } \\
\text { total of } 200 \text { mins }\end{array}$ \\
\hline $\begin{array}{l}\text { Online homework, } \sim 60-180 \text { mins } \\
\text { for every face-to-face session }\end{array}$ & $\begin{array}{l}\text { Online homework, } \sim 60-180 \mathrm{mins} \\
\text { for every face-to-face session }\end{array}$ & $\begin{array}{l}\text { Online homework, } \sim 60 \text { for } \\
\text { every face-to-face session }\end{array}$ \\
\hline
\end{tabular}

${ }^{*}$ Note: Number of participants per group reflects the number of participants who completed preand post-tests.

\section{Materials}

The control group used a beginner Spanish textbook and syllabus that had been used for the preceding five years, and that were being used by all of the other sections in the program at the time of the present study. The instructional approach that was used with the textbook varied 
from instructor to instructor across the program, and emphasis on the importance of completing the homework at home was indicated in the syllabus. Participants were introduced to new course content in the classroom, practiced it, and were then assigned online homework based on the new material, which was due before the subsequent class. The assignments participants did at home were worth $10 \%$ of the final grade. Finally, the syllabus included explicitly-stated learning outcomes that consisted of proficiency goals across the four skills.

Each experimental group utilized a different set of materials. They were textbooks published in the last two years by two different publishers, and were amenable in their design to being used specifically for flipped and blended/hybrid or online Spanish programs. The online component of these books presented the new materials to participants at home and engaged them in tasks comparable to structured input activities found in VanPatten's Processing Instruction (1996; 2004). That is, participants' attention was directed to notice the new forms in a context that allowed them to make form-meaning connections. Some of the tasks were to recognize the new target forms, and to fill out meaningful, contextualized drills. All four skills were practiced in the homework. Reading and listening were combined with production tasks for which participants were required to record short speech samples or produce mini-compositions. While most of the homework was computer-graded and the results were delivered immediately to the participants' and the instructor's dashboards, the writing and speaking assignments were hand-graded by the instructor, who was able to provide written and/or verbal feedback. The syllabus of the experimental sections showed a much heavier weight on the homework than the traditional section. The weight allotted to the assignments in the experimental sections was three times as heavy as in the control group. Thirty percent of their final grade depended on the completion and accuracy of their online tasks. The settings of the homework were set so that participants could change their answers on all computer-graded tasks up to two times if the first attempts did not yield a perfect score. Finally, the syllabus of the two experimental groups included the exact same explicitly-stated learning outcomes as the syllabus of the control group.

\section{Presentation of Teaching/Learning Approach to Participants}

Consistent with the other sections of the language program, the instructor of the control group (and the syllabus) emphasized the need for attendance and strong participation in order to increase the likelihood of success in the course but did not address any particular information regarding teaching methodology.

Unlike the rest of the sections, the experimental sections included the description of the new format ("flipped and blended classroom") on their syllabi. In order to establish clear expectations regarding homework, class work, and general class methodology, on the first day the instructors informed participants via slideshows and short talks what it meant to learn and teach in a flipped context. The use of the technology was reviewed in detail and the amount of time needed to complete the homework was clearly explained. Short reminders about this were repeated throughout the semester.

\section{Experimental Design and Instruments}

We followed a pre- and post-test design. All of our participants took a standardized online test, the STAMP 4s by Avant Assessment.

The pre-test was administered during the second and third weeks of the semester, and the post-test took place during the last two weeks of the semester-about 13-14 weeks later. The participants signed up to attend pre-scheduled time slots in the language laboratory. The scores range from 1 to 7 , following the STAMP test scale. ${ }^{5}$

The survey to gauge student perceptions on the new flipped model was administered during week 10 of the semester (see Appendix A) to participants in both experimental sections. It was 
administered as an anonymous survey through Blackboard. It consisted of ten multiple-choice as well as open-ended questions that tapped participants' understanding of what a flipped class entailed, their preferences of the new model compared to the more traditional format, their opinions on the user-friendliness of the textbooks' online materials, as well as suggestions on how to improve the quality of the course. A total of twenty-eight responses out of a possible thirty-nine were collected.

\section{Data Analysis}

A one-way ANOVA was run on the pre-test scores of sixty-two participants to determine that there were no significant differences between groups at the onset of the study with respect to any of the four skills tested (Table 2). The number of participants varied depending on the availability of ratable samples for each skill.

Table 2. One-way ANOVAs on pre-test scores of four skills

\begin{tabular}{lccccc}
\hline Source & $\boldsymbol{d} \boldsymbol{f}$ & Sums of Squares & Mean Squares & $\boldsymbol{F}$ & $\boldsymbol{p}$ \\
\hline Reading & 2 & 1.583 & .792 & .419 & .660 \\
Writing & 2 & .712 & .356 & .526 & .594 \\
Listening & 2 & .553 & .731 & .378 & .687 \\
Speaking & 2 & .347 & .173 & .337 & .717 \\
\hline${ }^{*} p<.05$ & & & & &
\end{tabular}

The raw scores obtained from the STAMP pre- and post-tests were collected and submitted to descriptive analysis (Table 3), and independent repeated measures ANOVAs were run on each skill (Tables 4-7), where the within-subject variable was time (pre- and post-test) and the between-subject variable was the type of group (Control, Experimental B or Experimental A).

Table 3. Descriptive statistics

\begin{tabular}{lccccc}
\hline \multirow{2}{*}{ Skill } & Group & Mean & Std. Deviation & N \\
\hline \multirow{2}{*}{ Pre-test } & Reading & C & 3.810 & 1.4703 & 21 \\
& & B & 3.500 & 1.2354 & 20 \\
& & A & 3.882 & 1.4090 & 17 \\
Post-test & Total & 3.724 & 1.3610 & 58 \\
& \multirow{3}{*}{ Reading } & C & 4.143 & 1.3522 & 21 \\
& & B & 4.250 & 1.2085 & 20 \\
Pre-test & A & 4.412 & 1.1213 & 17 \\
& Writing & Total & 4.259 & 1.2220 & 58 \\
& & C & 2.6111 & .91644 & 18 \\
& & B & 2.5263 & .77233 & 19 \\
& & A & 2.8235 & .80896 & 17 \\
& & Total & 2.6481 & .82776 & 54 \\
\hline
\end{tabular}


Table 3. (continued)

\begin{tabular}{|c|c|c|c|c|c|}
\hline & Skill & Group & Mean & Std. Deviation & $\mathbf{N}$ \\
\hline \multirow[t]{4}{*}{ Post-test } & Writing & $\mathrm{C}$ & 3.2222 & .54832 & 18 \\
\hline & & B & 3.4737 & .61178 & 19 \\
\hline & & A & 3.2353 & .75245 & 17 \\
\hline & & Total & 3.3148 & .63911 & 54 \\
\hline \multirow[t]{4}{*}{ Pre-test } & Listening & $\mathrm{C}$ & 2.3819 & .97346 & 21 \\
\hline & & B & 2.4000 & .88258 & 20 \\
\hline & & $\mathrm{A}$ & 2.1765 & .63593 & 17 \\
\hline & & Total & 2.3276 & .84579 & 58 \\
\hline \multirow[t]{4}{*}{ Post-test } & Listening & $\mathrm{C}$ & 2.333 & .91287 & 21 \\
\hline & & B & 2.5500 & .60481 & 20 \\
\hline & & A & 2.3529 & .70189 & 17 \\
\hline & & Total & 2.4138 & .75008 & 58 \\
\hline \multirow[t]{4}{*}{ Pre-test } & Speaking & $\mathrm{C}$ & 2.8889 & .78174 & 9 \\
\hline & & B & 2.6667 & .70711 & 9 \\
\hline & & A & 2.8750 & .35355 & 8 \\
\hline & & Total & 2.8077 & .63367 & 26 \\
\hline \multirow[t]{4}{*}{ Post-test } & Speaking & $\mathrm{C}$ & 3.111 & .78174 & 9 \\
\hline & & B & 2.8889 & .33333 & 9 \\
\hline & & A & 3.500 & .53452 & 8 \\
\hline & & Total & 3.1538 & .61269 & 26 \\
\hline
\end{tabular}

Table 4. Reading: Repeated measures ANOVA for group and time

\begin{tabular}{lrccrc}
\hline Source & $d \boldsymbol{f}$ & Type III Sum of Squares & Mean Squares & $\boldsymbol{F}$ & $\boldsymbol{p}$ \\
\hline Group & 2 & 1.375 & .688 & .259 & .773 \\
Time & 1 & 8.313 & 8.313 & 10.802 & $.002^{*}$ \\
Time* Group & 2 & .890 & .445 & .578 & .564 \\
Error & 55 & 42.326 & .770 & &
\end{tabular}

${ }^{*} p<.05$

Table 5. Writing: Repeated measures ANOVA for group and time

\begin{tabular}{lcccrc}
\hline Source & $d \boldsymbol{f}$ & Type III Sum of Squares & Mean Squares & $\boldsymbol{F}$ & $\boldsymbol{p}$ \\
\hline Group & 2 & .242 & .121 & .173 & .842 \\
Time & 1 & 11.622 & 11.622 & 28.673 & $.000^{*}$ \\
Time* Group & 2 & 1.329 & .664 & 1.639 & .204 \\
Error & 51 & 20.671 & .405 & &
\end{tabular}

${ }^{*} p<.05$ 
Table 6. Listening: Repeated measures ANOVA for group and time

\begin{tabular}{lccccc}
\hline Source & $d f$ & Type III Sum of Squares & Mean Squares & $\boldsymbol{F}$ & $\boldsymbol{p}$ \\
\hline Group & 2 & .825 & .412 & .414 & .663 \\
Time & 1 & .249 & .249 & .805 & .374 \\
Time $^{\star}$ Group & 2 & .298 & .149 & .482 & .620 \\
Error & 55 & 16.986 & .309 & & \\
\hline
\end{tabular}

${ }^{*} p<.05$

Table 7. Speaking: Repeated measures ANOVA for group and time

\begin{tabular}{lccccc}
\hline Source & $\boldsymbol{d f}$ & Type III Sum of Squares & Mean Squares & $\boldsymbol{F}$ & $\boldsymbol{p}$ \\
\hline Group & 2 & 1.432 & .716 & 1.262 & .302 \\
Time & 1 & 1.647 & 1.647 & 8.431 & $.008^{*}$ \\
Time $^{\star}$ Group & 2 & .449 & .225 & 1.150 & .334 \\
Error & 55 & 42.326 & .770 & & \\
\hline
\end{tabular}

${ }^{*} p<.05$

\section{Results}

The results of our analyses indicate that there was no main effect for Group at the pre-test (Table 2). At the post-test (Tables 4-7), there was no statistically-significant difference between Groups and no interactions between Time and Group for any other of the skills and small effect sizes: Reading $F(2,55)=0.259, p=.773, \eta^{2}=0.0416$; Writing $F(2,51)=0.173, p=.842, \eta^{2}=$ 0.009 ; Listening $F(2,55)=0.414, p=0.663, \eta^{2}=0.0148$; Speaking $F(2,55)=1.262, p=.302$, $\eta^{2}=0.043$. However, the descriptive statistics (Table 3 ) indicate that in the post-test, Experimental Group A outperformed the other two groups in Reading and Speaking, whereas Experimental Group B had more gains than the other groups in Writing and Listening. For Speaking, the Control Group yielded better results than Experimental Group B; it should be noted, however, that the power in that analysis was rather low (0.228) given that speaking samples of only 26 participants were deemed ratable by the STAMP raters.

Time, the within-subject variable, was significant for all skills except Listening (refer to Tables 4-7), indicating that for this skill there was no measurable improvement from the beginning to the end of the semester for the participants in any of the groups: Reading $F(1,55)=$ $10.802, p=0.002$; Writing $F(1,51)=28.673, p=0.000$; Listening $F(1,55)=0.805, p=0.374$; Speaking $F(1,55)=8.431, p=0.008 .^{6}$

The survey results provided us with rich and useful qualitative data that were key in the selection of the materials. From the pool of participants in Groups A and B who responded to the survey, $92.9 \%$ claimed that the term 'flipped' was clear to them. The remaining percentage did not answer the question. Slightly over $71 \%$ of participants responded that flipped was either 'way better' or 'somewhat better' than the traditional teaching model, while $25 \%$ declared to be undecided, and the rest did not answer the question. Among the reasons participants cited for liking the flipped model we found "I like the thought of being responsible for learning certain material outside of the class" and "The online homework is understandable yet challenging," indicating that participants are engaging in the material on their own. Another testimonial 
highlights one of the advantages of flipping a classroom: "I prefer to learn the class material at my own pace."

Among the complaints, we found a few related to the sporadic glitches and technical difficulties that come with using an online component. However, the general consensus seemed to be an enthusiastic thumbs-up for the flipped and blended model.

\section{Discussion}

The first research question asked what the effect of a flipped-blended course design would be on the development of the four skills, compared to a control group. Our results show that the sections using a flipped-blended format developed either the same, or more so, than the control group, and in a shorter amount of class time. While statistical results revealed non-significant differences across groups at the post-test stage, it is noteworthy that both experimental groups met face-to-face three days per week, as opposed to the control group's four days per week, and yet achieved the same statistical outcome. Descriptively, Group A outperformed Groups B and C in reading and speaking, whereas Group B outperformed the other groups in writing and listening. In either case, one of the experimental groups outperformed the control group in two skill areas, and in less time. Clearly, the experimental groups spent more time doing homework outside of the classroom, which we assert yielded a more appropriate use of classroom instruction, in that they were able to practice already-learned material in the classroom, as opposed to learning new material in the classroom. Furthermore, we assert that the flipped-blended model facilitated a more learner-centered instructional design because it required that students complete daily tasks with more agency, and on their own time, compared to the traditional instructional setting, in which they ultimately perform according to a predetermined structure. Our results lead us to ask what would have happened had each group met in the classroom four days per week. That is, the flipped-blended design appears to deliver instruction more efficiently; learners did at home that which did not need to be done in the classroom, and they only did in the classroom that which could not be accomplished at home. Learners moved through Leow's (2015) five stages of development with fewer contact hours in the classroom perhaps because the flipped-blended format allowed them to learn at their own pace, which we explain in more detail as we examine the results of our second research question.

The second research question sought to understand the learners' perceptions of the flippedblended model. Their answers provided us with a way to qualitatively infer why the experimental groups performed more efficiently than the control group. We credit the superiority of the experimental groups to the depth of processing inherent in the tasks involved in the flippedblended model. As Cerezo et al. (2015) noted, the use of technology as a medium of instruction led to more internalized language, more linguistic analysis, and more time for hypothesis testing. While their assertion refers to a videogame they designed specifically for increasing the depth of processing of a specific linguistic structure, we believe it applies to the present study as well, since our use of technology allowed us to control for type of instruction, for the level or depth of processing required for analyzing specific language in specific tasks, and for its ability to minimize the effect of different instructor characteristics across sections. Furthermore, their assertion is corroborated by the feedback we received from our L2 learners regarding the flipped-blended design. Learners' feedback centered around concepts of autonomy over the learning process, responsibility for doing the work, and working at one's own pace, all of which we associate with Leow's (2015) definition of depth of processing. Our experimental-group learners acknowledged the effort required in the learning process and credited it as a defining characteristic of the flipped-blended format. We interpret such self-reports as evidence of a more active involvement with input and the learning process. 
The impact of the pilot study described here on the overall curricular design of beginner language programs cannot be overstated. From a departmental perspective, several administrative, pedagogical, and logistical challenges are overcome. First, our study shows that a greater depth of processing may be achieved by using a flipped model, in which more time learning the language is spent at home, and more time practicing the language is spent in the classroom, supporting previous calls for this type of curricular model (Cerezo et al. 2016; Leow, et al. 2019). Second, when the template for the present study is applied to forty sections, the underlying principles of learning that guide the pedagogy are built into the computerized delivery of each section, thus fostering uniformity. Third, more class time may be used for learning content, such as cultural or literary analysis, which thus makes the notion of moving beyond the two-tier structure of language programs more feasible. Finally, our results show that proficiency-based outcomes may more efficiently be achieved using a cognitive model of language learning to guide a blended and flipped model of instruction.

\section{Conclusion}

The present study aimed at accomplishing that which the MLA's 2007 report called for: to restructure a foreign language program according to principles established by SLA research, with the goal of meeting the increasing demands for proficiency-based learning outcomes. In doing so, it provided a template for implementing a cognitive framework of language processing in a pedagogical design, structured in such a way as to increase the depth of language processing using a flipped approach, and delivered in a blended computerized and face-to-face format to maximize efficiency of learning. Our results showed that doing so achieved similar, or greater, development of proficiency than a traditional control group, using less class time, and thus provides a template for other language programs to utilize, as they attempt to develop according to the growing demands for multilingualism by producing more proficient users of foreign language.

The study described here, however, also generated more questions than answers. Future research should continue to explore how foreign language instruction can be restructured among institutions of higher learning, and how proficiency-based learning outcomes may be achieved. From a methodological perspective, it would be helpful to see what a longitudinal study, covering three or four semesters, would reveal regarding proficiency development, since our study only examined growth over the course of one semester. It would also be important to investigate the type of teacher training that would be necessary for preparing instructors to teach using a flipped-blended design. To what extent would instructor characteristics affect the type of practice conducted in classroom settings? In addition, our study explored but one aspect of the MLA's call for restructuring, which was the incorporation of SLA theory in foreign language pedagogy. Research investigating how we may move beyond the two-tier structure of foreign language programs remains to be sufficiently explored. How can constructs such as depth of language processing be incorporated into upper-division (major) content courses? And how can a cognitive model of language processing, itself, be incorporated into all levels of language instruction and assessment?

\section{NOTES}

${ }^{1}$ From this point forward, we use the acronym ISLA to refer to research investigating specific effects of pedagogical intervention and contexts on the learning process, as opposed to SLA, which refers to more general theories of acquisition.

${ }^{2}$ The present study adopts the latter, cognitive / psycholinguistic framework, to explain instructional design and learner performance, as they relate to our experimental and control groups. 


\footnotetext{
${ }^{3}$ The present study does not explore the effects of implicit versus explicit instruction, nor does it argue for or against specific interface positions.

${ }^{4}$ The present study uses the term 'blended' to refer to a course in which $25 \%$ of instruction is delivered via computer.

${ }^{5}$ According to Avant Assessment, STAMP test scores are aligned with ACTFL's levels as follows: $1=$ Novice-Low; $2=$ Novice-Mid; $3=$ Novice High; $4=$ Intermediate-Low; $5=$ Intermediate-Mid; $6=$ Intermediate-High; 7 = Advanced-Low.

${ }^{6}$ That all groups improved in all skills except for listening leaves us to speculate that the course designs may have been biased toward reading, speaking, and writing. Future research could more closely examine the extent to which each skill is targeted in instructional design.
}

\section{WORKS CITED}

Adair-Hauck, Bonnie, et al. (2010). "Using a Story-based Approach to Teach Grammar.” Teacher's Handbook: Contextualized Foreign Language Instruction 4th ed., edited by Judith L. Shrum and Eileen W. Glisan, Heinle, Cengage Learning, pp. 216-44.

Allen, I. Elaine, and Jeff Seaman. (2014). "Grade Change." Tracking Online Education in the United States. Babson Survey Research Group and Quahog Research Group, p. 5.

Berman, Russell A. (2012). Presidential Address. Annual MLA Convention. www.mla.org/Convention /Convention-History/MLA-Presidential-Addresses/2011-15-Presidential-Addresses/2012-Presidential -Address.

Carroll, Suzanne. (2001). Input and Evidence: The Raw Material of Second Language Acquisition. John Benjamins.

Cerezo, Luis, et al. (2015). "12 Psycholinguistically Motivated CALL Activities." A Psycholinguistic Approach to Technology and Language Learning, vol. 11, pp. 243.

Cerezo, Luis, et al. (2016). "The Effectiveness of Guided Induction versus Deductive Instruction on the Development of Complex Spanish Gustar Structures." Studies in Second Language Acquisition, vol. 38, no. 2, pp. 265-91.

DeKeyser, Robert. (2007). "Situating the Concept of Practice." Practice in a Second Language: Perspectives from Applied Linguistics and Cognitive Psychology, edited by Robert DeKeyser, Cambridge UP.

DeKeyser, Robert, and Goretti Prieto Botana. (2013). "Acquisition of Grammar by Instructed Learners." The Handbook of Spanish Second Language Acquisition, edited by Kimberly Geeslin, Wiley.

Donato, Richard, and Bonnie Adair-Hauck. (2016). "PACE: A Story-Based Approach for Dialogic Inquiry about Form and Meaning." Teacher's Handbook: Contextualized Foreign Language Instruction, 5th ed., edited by Judith L. Shrum and Eileen W. Glisan, Cengage Learning, pp. 206-30.

Ellis, Nick. (2002). "Frequency Effects in Language Processing." Studies in Second Language Acquisition, vol. 2, no. 2, pp. 143-88.

Ellis, Rod. (2016). "Focus on Form: Past and Present." Plenary presented at the Second Language Research Forum, Columbia U, 2016 Sept. 23.

"Foreign Languages and Higher Education: New Structures for a Changed World." (2007). Modern Language Association (MLA) Report. www.mla.org/Resources/Research/Surveys-Reports-and-Other -Documents/Teaching-Enrollments-and-Programs/Foreign-Languages-and-Higher-Education-New -Structures-for-a-Changed-World.

Gurzynski-Weiss, Laura. (2013). "Instructor Characteristics and Classroom-Based Second Language Acquisition of Spanish." The Handbook of Spanish Second Language Acquisition, edited by Kimberly Geeslin, Wiley-Blackwell, pp. 530-46.

Krashen, Stephen. (1982). Principles and Practice in Second Language Acquisition. Pergammon.

Krashen, Stephen, and Tracy D. Terrell. (1983). The Natural Approach: Language Acquisition in the Classroom. Prentice Hall.

Leow, Ronald P. (2015). Explicit Learning in the L2 Classroom: A Student-centered Approach. Routledge.

Leow, Ronald P., and Luis Cerezo. (2016). "Deconstructing the I and SLA in ISLA: One Curricular Approach." Studies in Second Language Learning and Teaching, vol. 1, no. 1, pp. 43-63.

Leow, Ronald P., et al. (2019). "CALL in ISLA: Promoting Depth of Processing of Complex L2 Spanish 'Para / Por' Prepositions." SLA Research with Implications for the Classroom (Reconciling Methodological Demands and Pedagogical Applicability, edited by Robert DeKeyser and Goretti Prieto Botana, John Benjamins, pp. 155-78. 
Loewen, Shawn. (2015). Introduction to Instructed Second Language Acquisition. Routledge.

Malovrh, Paul A., and Alessandro G. Benati, editors. (2018). The Handbook of Advanced Proficiency in Second Language Acquisition. Wiley.

Malovrh, Paul A., and Nina Moreno. (2018). "Meeting the Demands of Globalization: One Goal of ISLA Research." The Handbook of Advanced Proficiency in Second Language Acquisition, edited by Paul A. Malovrh and Alessandro Benati, Wiley, pp. 199-218.

Moreno, Nina. (2014) “The Place of Individual Differences in Foreign Language Teaching Assistants' Education Programs.” Individual Differences, L2 Development and Language Program Administration: From Theory to Application, edited by Cristina Sanz and Bea Lado, American Association of University Supervisors and Coordinators (AAUSC) 2013 annual volume, Heinle, pp. 128-49.

Norris, John M., and Lourdes Ortega. (2000). "Effectiveness of L2 Instruction: A Research Synthesis and Quantitative Meta-Analysis.” Language Learning, vol. 50, no. 2, pp. 417-528.

Redden, Elizabeth. (2017). "Call to Action on Languages, 10 Years Later." Inside Higher Ed. 6 January 2017. www .insidehighered.com/news/2017/01/06/survey-looks-foreign-language-programs-response-decade -old-call-transform-teaching.

VanPatten, Bill. (1996). Input Processing and Grammar Instruction in Second Language Acquisition. Erlbaum. . (2007). "Input Processing in Adult Second Language Acquisition." Theories in Second Language Acquisition, edited by Bill VanPatten and Jessica Williams, Erlbaum, pp. 115-35.

—. (2015). "Where Are the Experts?" Hispania, vol. 98, no. 1, pp. 2-13.

VanPatten, Bill, editor. (2004). Processing Instruction: Theory, Research, and Commentary. Routledge.

VanPatten, Bill, and Jessica Williams, editors. (2007). Theories in Second Language Acquisition: An Introduction. Routledge.

Zhuang, Jingyuan. (2019). "Computer-Assisted Guided Induction and Deductive Instruction on the Development of Complex Chinese ba Structures: Extending Cerezo, Moreno, and Leow (2016).” The Routledge Handbook of Second Language Research in Classroom Learning, edited by Ronald P. Leow, Routledge, pp. 391-406.

\section{APPENDIX}

This is an anonymous survey that I am asking you to please fill out. It will provide the Spanish Program with important info re. the materials we are using, and the new blended and flipped class format. While the answers will not be linked to anyone's name, the system will inform me who has completed the survey and who has not. If you do not complete the form, you will lose participation points.

Question 1. I understand what a 'flipped' class means.

a. true

b. false

Question 2. Using the Likert scale below, state how much you like the model we are using in class this semester (flipped) versus the traditional model, where flipped means that the new information is learned at home so that we can practice with the new structures in class, and a traditional model is one in which the grammar or vocabulary is explained in class and then some practice of that is done at home as homework.

1. Flipped is way better!

2. Flipped is somewhat better than traditional.

3. Still undecided or unsure about which model I prefer.

4. Traditional is somewhat better than flipped.

5. Bring traditional back!

Question 3. Explain your answer in question \#2. 
Question 4. I enjoy working / learning with the materials we have in class (i.e., name of textbook, online component).

1. strongly agree

2. agree

3. neither agree nor disagree

4. disagree

5. strongly disagree

Question 5. Explain your answer in question \#4.

Question 6. Rank the following components, where 1 is the component you liked the most, 2 is the second best, and so on.

1. display order

2. ease of navigation

3. grammar and vocabulary explanations

4. grammar and vocabulary 'apply' exercises (the ones you do after you have gone over the explanations)

5. culture contents/videos

6. extra resources (flashcards, extra practice activities, videos, etc.)

Question 7. I feel that I can use the resources (textbook) has through the online component to learn and practice what I am unsure about.

a. true
b. false

Question 8. What do you like most about this class?

Question 9. What do you dislike most about this class?

Question 10. How can we improve this course this semester or for when it is taught in the future? 